
2 Research Square
Preprints are preliminary reports that have not undergone peer review.
They should not be considered conclusive, used to inform clinical practice,
or referenced by the media as validated information.

\title{
An NADPH-auxotrophic Corynebacterium glutamicum recombinant strain and used it to construct L-leucine high-yielding strain
}

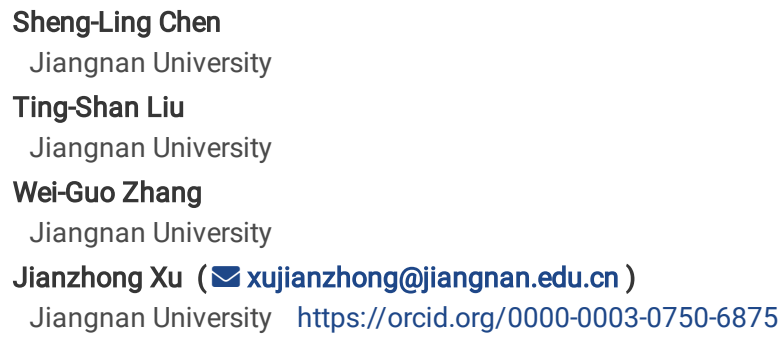

\section{Research Article}

Keywords: Corynebacterium glutamicum, NADPH auxotroph, Promoter engineering, L-leucine production

Posted Date: April 13th, 2022

DOI: https://doi.org/10.21203/rs.3.rs-1270501/v2

License: () (1) This work is licensed under a Creative Commons Attribution 4.0 International License. Read Full License 


\section{Abstract}

The NADPH-regeneration enzymes in Corynebacterium glutamicum were inactivated to construct an NADPH-auxotrophic $C$. glutamicum strain by gene knockout and gene replacement. The resultant NADPH-auxotrophic $C$. glutamicum XL-1 $\Delta \mathrm{ZMI} \mathrm{Cg}_{\mathrm{Cg}}: \mathrm{I}_{\mathrm{Sm}}$ (i.e., strain Leu-1) grew well in the basic medium only with gluconate as carbon source. Replacement of the native glyceraldehyde 3-phosphate dehydrogenase (NAD-GapDH $\mathrm{Cg})$ by $\mathrm{NADP}^{-\mathrm{GapDH}_{\mathrm{Ca}}}$ from Clostridium acetobutylicum is an effective strategy for producing L-leucine in NADPH-prototrophic strain XL-1 and NADPH-auxotrophic strain Leu-1, whereas the L-leucine yield did not differ significantly between these strains $(14.1 \pm 1.8 \mathrm{~g} / \mathrm{L}$ v.s. $16.2 \pm 1.1 \mathrm{~g} / \mathrm{L})$. Enhancing the carbon flux in biosynthetic pathway by recombinant expression plasmid pEC-ABNCE promoted L-leucine production, but the shortage NADPH supply limited the L-leucine yield. The mutated promoters of $z w f$ and $i c d_{\mathrm{Cg}}$ were introduced into $C$. glutamicum with NADP-GapDH $\mathrm{Ca}_{\text {and }}$ pEC-ABNCE increased L-leucine yield $(32.8 \pm 1.7 \mathrm{~g} / \mathrm{L})$ and improved cell growth $\left(\mathrm{OD}_{562}=\right.$ $41.3 \pm 4.2$ ) because the resultant strain $C$. glutamicum $X \mathrm{~L}-1 \Delta \mathrm{MI}_{\mathrm{Cg}}:: \mathrm{I}_{\mathrm{Sm}} \mathrm{G}_{\mathrm{Cg}}:: \mathrm{G}_{\mathrm{Ca}} P_{\mathrm{zwf}} \mathrm{D} 1 P_{\mathrm{icd}}-\mathrm{D} 2 / \mathrm{pEC}-\mathrm{ABNCE}$ (i.e., strain Leu-9) exhibited the proper intracellular NADPH and NADH level. This is the first report of constructing an L-leucine high-yielding strain that reasonably supplies NADPH by optimizing the biosynthetic pathway of NADPH from an NADPH-auxotrophic strain.

\section{Introduction}

L-leucine is one of the essential amino acids for animal and human that needs to add into feed or food to meet the requirement of animal and human (Wang et al. 2019a). Given the important roles of L-leucine, it has been widely used as feed additive or nutritional supplement in feed or food industry (Luo et al. 2021; Wang et al. 2021). In addition, it is also widely used in chemical and pharmaceutical industry as cosmetic ingredient and medical intermediate, respectively (Ma et al. 2021; Wang et al. 2020). Although L-leucine would be produced by albuminolysis and enzymatic synthesis, microbial fermentation using Corynebacterium glutamicum as work-horse has become the mainstream method to produce L-leucine in industry at present because of the lowest environmental pollution and the best economic effect (Wang et al. 2020). Thus, the L-leucine producing strain with excellent fermentation performance is vital to increase the final titer and to reduce the production cost. To construct an L-leucine high-yielding strain, it not only needs to enhance the carbon flux in $\mathrm{L}$ leucine biosynthetic pathway, but also needs to balance the supply of REDOX cofactor [i.e., $\mathrm{NAD}\left(\mathrm{H} /{ }^{+}\right)$and $\left.\mathrm{NADP}\left(\mathrm{H} /^{+}\right)\right]$.

The effect of NADPH in amino acids production has been discussed by Xu et al. (2019), and Wang et al. pointed out that NADPH shortage is a rate-limiting factor for increasing L-leucine production (Wang et al. 2019b). As can be seen from Fig. 1, 2 molecules NADPH involve in L-leucine biosynthesis at acetohydroxyacid isomeroreductase (AHAIR)-catalyzed reaction and branched-chain amino acid transaminase (BCAT)-catalyzed reaction. In C. glutamicum, four enzymes were reported to involve in NADPH biosynthesis, i.e., glucose-6-phosphate dehydrogenase (Zwf), 6-phosphogluconate dehydrogenase (Gnd), NADP-dependent isocitrate dehydrogenase (NADP-Icd) and malic enzyme (MalE)(Fig. 1) (Hoffmann et al. 2021; Xu et al. 2019). However, the Zwf and Gnd in pentose phosphate (PP) pathway are the main enzymes for NADPH regeneration (Lindner et al. 2018). Increasing the activity of these key enzymes involved in NADPH biosynthesis is one of the most common strategies in constructing NADPH-dependent products high-producing strain (Xu et al. 2018). This is mostly achieved by increasing gene copies or replacing the native promoter by a strong promoter, or relieving the feedback regulation of enzyme (Li et al. 2016; Xu et al. 2018). Although these strategies have acquired certain positive results, the negative factor as the shadow follows the form. For example, enhancement the carbon flux in PP pathway by overexpression of Zwf- and Gnd-coding gene not only improves NADPH supply but also increases the release of $\mathrm{CO}_{2}$ ( $\mathrm{Jiang}_{\mathrm{ian}}$ et al. 2013; Yuan et al. 2021). Moreover, irrational supply of NADPH results in the excesses of intracellular NADPH, thus leading to more reactive oxygen species (ROS) production and to injure cells (Xu et al. 2019; Zhu et al. 2021). Therefore, how to optimize the NADPH-supplying pathway under no background noise is important for constructing NADPH-dependent products producing strains with excellent fermentation performance.

In 2018, the researchers in Arren Bar-Even's Lab from Max Planck Institute of Molecular Plant Physiology (Potsdam-Golm, Germany) constructed an Escherichia coli NADPH-auxotroph strain via inactivation of enzymes in NADPH biosynthetic pathway (Lindner et al. 2018), and used it as chassis strain to select formate dehydrogenase variants with high efficiency and specificity toward NADP ${ }^{+}$(Calzadiaz-Ramirez et al. 2020). Refer to the above experimental considerations, therefore, the objective of this study was to try to construct an L-leucine high-producing strain based on optimizing NADPH-supplying pathway from C. glutamicum NADPH-auxotroph strain. The main methods of this study involved in three aspects: (1) constructing a $C$. glutamicum NADPH-auxotroph strain via inactivation of enzymes in NADPH biosynthetic pathway from an L-leucine producing strain C. g/utamicum XL-1 (Wang et al. $2019 \mathrm{~b})$; (2) replacing the native $\mathrm{NAD}$-dependent glyceraldehyde 3-phosphate dehydrogenase $\left(\mathrm{NAD}-\mathrm{GapDH}_{\mathrm{Cg}}\right.$ ) by $\mathrm{NADP}^{-\mathrm{GapDH}_{\mathrm{Ca}}}$ from Clostridium acetobutylicum; $(3)$ rationally regulating the expression levels of Zwf-coding gene $z w f$ via promoter engineering. As a result, a high-yielding strain $C$. glutamicum Leu-9 with constructed weak promoter of $z w f$ was obtained, which produced $32.8 \pm 1.7 \mathrm{~g} / \mathrm{L}$ of L-leucine in 72 -h shake flask fermentation. Here, we report an effective strategy to construct an L-leucine high-producing strain from an NADPH-auxotrophic strain by optimizing the biosynthetic pathway of NADPH for the first time. The design-based strategy for constructing L-leucine high-yielding strain reported here could serve as a general concept for breeding NADPH-dependent products high-yielding strains.

\section{Materials And Methods}

\section{Strains, growth medium and culture conditions}

Strains used in this study are listed in Table 1. The parental strain C. glutamicum XL-1 was an L-leucine producing strain constructed by Wang et al. ( 2019b). E. coli and C. glutamicum were cultivated in Luria-Bertani (LB) medium at $37^{\circ} \mathrm{C}$ and in LB-glucose (LBG) medium at $30^{\circ} \mathrm{C}$, respectively $(\mathrm{Xu}$ et al. 2016$)$. CgXII medium, consisting of (per liter) $42 \mathrm{~g}$ of 3-morpholinopropanesulfonic acid, $20 \mathrm{~g}$ of $\left(\mathrm{NH}_{4}\right)_{2} \mathrm{SO}_{4}, 5 \mathrm{~g}$ of urea, $1 \mathrm{~g}$ of $\mathrm{KH}_{2} \mathrm{PO}_{4}, 1 \mathrm{~g} \mathrm{of} \mathrm{K} \mathrm{HPO}_{4} \cdot 3 \mathrm{H}_{2} \mathrm{O}, 0.25 \mathrm{~g}$ of $\mathrm{MgSO}_{4} \cdot 7 \mathrm{H}_{2} \mathrm{O}, 0.01 \mathrm{~g}$ of $\mathrm{CaCl}_{2}, 0.01 \mathrm{~g}$ of $\mathrm{FeSO}_{4} \cdot 7 \mathrm{H}_{2} \mathrm{O}, 0.01 \mathrm{~g}$ of $\mathrm{MnSO}_{4} \cdot \mathrm{H}_{2} \mathrm{O}, 0.01 \mathrm{~g}$ of $\mathrm{ZnSO}_{4} \cdot 7 \mathrm{H}_{2} \mathrm{O}, 0.0002 \mathrm{~g}$ of NiCl$\cdot 6 \mathrm{H}_{2} \mathrm{O}, 0.0002 \mathrm{~g}$ of biotin and $0.00003 \mathrm{~g}$ of protocatechuic acid,(Keilhauer et al. 1993) was used for growth experiments. $36 \mathrm{~g}$ of glucose or the equivalent other carbon sources (calculating based on the energy of combustion among these carbon sources (Lindner et al. 2018)) were used as the carbon source. Appropriately, $50 \mu \mathrm{g} / \mathrm{mL}$ or $25 \mu \mathrm{g} / \mathrm{mL} \mathrm{kanamycin}$ 
(Kan) solution was used to screen the target plasmids and strains. In addition, $1 \mathrm{mmol} / \mathrm{L}$ isopropyl $\beta$-D-thiogalactopyranoside (IPTG) solution was used to induce gene overexpression. 
Table 1

The main strains and plasmids used in this study

\begin{tabular}{|c|c|c|}
\hline Strains and plasmids & Characters & Reference \\
\hline \multicolumn{3}{|l|}{ C. glutamicum strains } \\
\hline ATCC13032 & Wild-type strain & Stratagene \\
\hline XQ-9 & C. glutamicum a-AB ${ }^{r} 2-\mathrm{TA}^{r} \mathrm{SG}^{\mathrm{r}} \beta-\mathrm{HL}^{r}{ }^{\mathrm{r}} \mathrm{le}^{-}$Met $^{-}$, a L-leucine producing strain derived from strain ATCC13032 & $\begin{array}{l}\text { (Wang et al., } \\
2019 \text { b) }\end{array}$ \\
\hline $\mathrm{XL}-1$ & Strain XQ-9 derivative with in-frame deletion of $I t b R$ & $\begin{array}{l}\text { (Wang et al., } \\
2020 \text { ) }\end{array}$ \\
\hline Leu-1 & $\begin{array}{l}\text { An NADPH-auxotrophic strain derived from strain XL-1 with inactivated Zwf and MalE as well as replacement } \\
\text { with NAD-dependent Icd }\end{array}$ & This study \\
\hline Leu-2 & The native NAD-dependent GapDH was replaced by NADP-dependent GapDH in strain Leu- 1 chromosome & This study \\
\hline Leu-3 & $\begin{array}{l}\text { The native promoter of gene } z w f \text { was replaced by promoter } P_{\mathrm{zwf}} \mathrm{D} 5 \text { in strain Leu- } 2 \text { chromosome and harboring } \\
\text { plasmid pEC-ABNCE }\end{array}$ & This study \\
\hline Leu-4 & $\begin{array}{l}\text { The native promoter of gene } z w f \text { was replaced by promoter } P_{\mathrm{zwf}} \mathrm{D} 1 \text { in strain Leu- } 2 \text { chromosome and harboring } \\
\text { plasmid pEC-ABNCE }\end{array}$ & This study \\
\hline Leu-5 & $\begin{array}{l}\text { The native promoter of gene } z w f \text { was replaced by promoter } P_{\mathrm{zwf}} \mathrm{S} 6 \text { in strain Leu- } 2 \text { chromosome and harboring } \\
\text { plasmid pEC-ABNCE }\end{array}$ & This study \\
\hline Leu-6 & $\begin{array}{l}\text { The native promoter of gene icd was replaced by promoter } P_{\text {icd }} \text {-D2 in strain Leu- } 2 \text { chromosome and harboring } \\
\text { plasmid pEC-ABNCE }\end{array}$ & This study \\
\hline Leu-7 & $\begin{array}{l}\text { The native promoter of gene } z w f \text { was replaced by promoter } P_{\text {icd }} \text {-S7 in strain Leu- } 2 \text { chromosome and harboring } \\
\text { plasmid pEC-ABNCE }\end{array}$ & This study \\
\hline Leu-8 & $\begin{array}{l}\text { The native promoter of gene } z w f \text { was replaced by promoter } P_{\text {icd }}{ }^{-T} 3 \text { in strain Leu- } 2 \text { chromosome and harboring } \\
\text { plasmid pEC-ABNCE }\end{array}$ & This study \\
\hline Leu-9 & $\begin{array}{l}\text { The native promoters of genes } z w f \text { and } i c d \text { were replaced by promoter } P_{\mathrm{zwf}} \mathrm{D} 1 \text { and } P_{\mathrm{icd}}-\mathrm{D} 2 \text { in strain Leu- } 2 \\
\text { chromosome and harboring plasmid pEC-ABNCE }\end{array}$ & This study \\
\hline Leu-10 & $\begin{array}{l}\text { The native promoters of genes } z w f \text { and } i c d \text { were replaced by promoter } P_{\mathrm{zwf}} \text {-D1 and } P_{\text {icd }}{ }^{-S 7} \text { in strain Leu-2 } \\
\text { chromosome and harboring plasmid pEC-ABNCE }\end{array}$ & This study \\
\hline Leu-11 & $\begin{array}{l}\text { The native promoters of genes } z w f \text { and } i c d \text { were replaced by promoter } P_{\mathrm{zwf}} \mathrm{D} 1 \text { and } P_{\mathrm{icd}}{ }^{-\mathrm{T} 3} \text { in strain Leu-2 } \\
\text { chromosome and harboring plasmid pEC-ABNCE }\end{array}$ & This study \\
\hline \multicolumn{3}{|l|}{ Plasmids } \\
\hline pEC-XK99E & Kan', Expression vector with $p M B 1$ replicon & Stratagene \\
\hline pEC-ABNCE & $\mathrm{Kan}^{\mathrm{r}}$, pEC-XK99E derivative containing gene leuA, ilvBN, ilvC and ilvE & $\begin{array}{l}\text { (Wang et al., } \\
\text { 2019b) }\end{array}$ \\
\hline $\mathrm{pEC}-\mathrm{ABNC} \mathrm{M}^{\mathrm{M}}$ & $\begin{array}{l}\text { Kan }{ }^{r}, \text { pEC-ABNCE derivative integrated mutations into ilvC coding for amino acid exchanges S34G, L48E, and } \\
\text { R49F }\end{array}$ & $\begin{array}{l}\text { (Wang et al., } \\
2019 \mathrm{~b})\end{array}$ \\
\hline pDXW-11 & $\mathrm{Kan}^{\mathrm{r}}$, E. coli-C. glutamicum shuttle probe vector & $\begin{array}{l}\text { (Xu et al., } \\
2011)\end{array}$ \\
\hline $\mathrm{pDXW}-11-P_{\mathrm{M}}$ & 400-bp insert with the gene $M$ promoter region (gene $M$ represented $z w f$, gnd, icd, malE and gapA) & This study \\
\hline pK18mobsacB & Integration vector & Stratagene \\
\hline $\begin{array}{l}\text { pK18mobsacB/ } \\
\Delta P_{\mathrm{zwf}}\end{array}$ & Integration vector for deleting the promoter of $z w f$ & This study \\
\hline $\begin{array}{l}\text { pK18mobsacB/ } \\
\Delta P_{\text {male }}\end{array}$ & Integration vector for deleting the promoter of malE & This study \\
\hline $\begin{array}{l}\text { pK18mobsacB/ } \\
\text { iicd }_{\mathrm{Cg}}: \text { icd }_{\mathrm{Sm}}\end{array}$ & Integration vector for replacement of the ORF of $i c d_{\mathrm{Cg}}$ gene by the ORF of $i c d_{\mathrm{Sm}}$ gene & This study \\
\hline $\begin{array}{l}\text { pK18mobsacB/ } \\
\Delta g a p A:: g a p C\end{array}$ & Integration vector for replacement of the ORF of gapA gene by the ORF of gapC gene & This study \\
\hline $\begin{array}{l}\mathrm{pK} 18 m o b s a c B / \\
\Delta P_{\mathrm{zwf}}: P_{\mathrm{zwf}} \mathrm{M}\end{array}$ & $\begin{array}{l}\text { Integration vector for replacement of the promoter of } z w f \text { gene by the mutated promoter of } z w f \text { gene (i.e., } P_{\mathrm{zwf}} \\
\mathrm{D} 5, P_{\mathrm{zwf}}-\mathrm{D} 1 \text { and } P_{\mathrm{zwf}} \mathrm{S} 6 \text { ) }\end{array}$ & This study \\
\hline $\begin{array}{l}\text { pK18mobsacB/ } \\
\Delta P_{\text {icd }:: P_{\text {icd }}-\mathrm{M}}\end{array}$ & $\begin{array}{l}\text { Integration vector for replacement of the promoter of } i c d \text { gene by the mutated promoter of } i c d \text { gene (i.e., } P_{\text {icd }}{ }^{-D 2,} \\
P_{\text {icd }}-\text { S7 and } P_{\text {icd }}{ }^{-T 3} \text { ) }\end{array}$ & This study \\
\hline
\end{tabular}


Batch shake-flask fermentation was carried out in $500 \mathrm{~mL}$ shake flask with $50 \mathrm{~mL}$ of fermentation medium, and was referred to the methods described by Feng et al (2018). Inoculum was from a seed culture with $\Delta \mathrm{OD}_{562}=0.45-0.50$ (at a dilution of 25 -fold), and the inoculation amount was $10 \%$. The seed medium was prepared according to the previous reports described by Wang et al.(2020) And the fermentation medium was prepared according to the following formula (per liter): $130 \mathrm{~g}$ glucose, $25 \mathrm{~g}$ corn steep powder, $15 \mathrm{~g}\left(\mathrm{NH}_{4}\right)_{2} \mathrm{SO}_{4}, 15 \mathrm{~g} \mathrm{CH}_{3} \mathrm{COONH}_{4}, 2 \mathrm{~g} / \mathrm{L} \mathrm{Na}_{3} \mathrm{C}_{6} \mathrm{H}_{5} \mathrm{O}_{7} \cdot 2 \mathrm{H}_{2} \mathrm{O}, 2 \mathrm{~g} / \mathrm{L}$ urea, $1 \mathrm{~g} \mathrm{KH} \mathrm{PO}_{4}, 0.5$ $\mathrm{g} / \mathrm{L} \mathrm{MgSO}_{4} \cdot 7 \mathrm{H}_{2} \mathrm{O}, 0.01 \mathrm{~g} / \mathrm{L} \mathrm{MnSO}_{4} \cdot \mathrm{H}_{2} \mathrm{O}, 0.7 \mathrm{~g} / \mathrm{L} \mathrm{L-methionine,} 0.5 \mathrm{~g} / \mathrm{L} \mathrm{L-glutamate}, 0.06 \mathrm{~g} / \mathrm{L} \mathrm{L}$-isoleucine, $160 \mu \mathrm{g} / \mathrm{L}$ thiamine $\mathrm{HCl}, 50 \mu \mathrm{g} / \mathrm{L}$ biotin and $30 \mathrm{~g} / \mathrm{L}$ $\mathrm{CaCO}_{3}$. Media were adjusted to $\mathrm{pH} 7.3$ with $20 \%(\mathrm{~m} / \mathrm{v}) \mathrm{NaOH}$.

\section{Construction of $\mathrm{C}$. glutamicum recombinant strains}

Plasmids and oligonucleotides used in this study are listed in Table 1 and Supplementary material (Table S1), respectively. Plasmid pEC-XK99E was used for gene expression, and plasmid pK18mobsacB was used for gene deletions and gene replacements in $C$. glutamicum. The detail methods used for gene modification (i.e., gene expression, gene deletion and gene replacement) were referred to the published method (Liu et al., 2021). To construct Zwf- and/or MalE-deficient strain, the promoters of gene $z w f$ and/or malE were deleted. The cassettes of $g a p C_{\mathrm{Ca}}$ with the $P_{\mathrm{gapA}}$ promoter, $r r n B T 1 T 2$ terminator and $E c o \mathrm{RI}$ endonuclease was optimized for expression in $C$. glutamicum and then synthetized by GENEWIZ (Suzhou), Inc. (Suzhou, China). The detail processes of plasmid construction were listed in Supplementary material (Figure S1). For modifying promoter, fragments ( 400 bp) carrying promoters of the genes zwf, gnd, malE, gapA and icd were amplified from the chromosome of $C$. glutamicum XL-1 by PCR with corresponding primers (Table S1). The PCR products after gel purification were digested by the corresponding restriction endonucleases and cloned in the plasmid pDXW-11 (Xu et al., 2011). The resultant plasmids were transferred into C. glutamicum by electroporation, and the target recombinants were selected referring to the published method (van der Rest et al. 1999).

\section{Preparation of crude enzyme and enzyme activity assays}

The cells in the logarithmic growth were collected after centrifugation for $10 \mathrm{~min}$ at $5000 \times g$, and then were disrupted by sonication. Following, fragmentized liquid was centrifuged by centrifuge at $4^{\circ} \mathrm{C}$ and $10000 \times \mathrm{g}$ for $30 \mathrm{~min}$, and then the cell-free supernatants were used as crude enzyme to determine the enzyme activities. Protein concentrations were analyzed using the Bradford Protein Quantification Kit (Vazyme, Nanjing, China) with bovine serum albumin as standard. The enzyme activity assays were done in triplicate, and the analytical methods of Zwf, Gnd, IDH, MalE, GapDH and chloramphenicol acetyltransferase (CAT) were based on the protocol of Tran et al. (2021), Cardinali-Rezende et al. (2020), Wang et al. (Wang et al., 2015), Hörl et al. (2021), Xu et al. (2014) and Holátko et al. (2009), respectively.

\section{Quantification of intracellular pyridine nucleotides}

The intracellular pyridine nucleotides (i.e., NADH/NAD and NADPH/NADP) of cells cultivated for $36 \mathrm{~h}$ were extracted referring to the published method (Faijes et al. 2007), and the concentration was detected using NAD/NADH Quantification Colorimeteric Kit or NADP/NADPH Quantification Colorimeteric Kit (BioVision, Inc., Milpitas, CA) based on the manufacturer's instructions, respectively.

\section{Analytical methods}

A sample was taken from the shake flasks at the right time. The sample was used to analyze cell growth using a spectrophotometer at $562 \mathrm{~nm}$ after an appropriate dilution. In addition, glucose concentration was determined using an SBA-40E immobilized enzyme biosensor (Shandong, China). The concentration of L-leucine was determined by high performance liquid chromatography (HPLC) using Agilent 1200 system (Agilent Technologies, Santa Clara, CA, USA) according to the procedure described by Wang et al. (2020).

\section{Results}

Construction and characterization of an NADPH-auxotrophic C. glutamicum strain

In C. glutamicum, there are four enzymes that are reported to involve in NADPH regeneration (Fig. 1) (Hoffmann et al. 2021; Xu et al. 2019). In order to construct an NADPH-auxotrophic $C$. glutamicum strain, we aimed to inactivate the $Z_{w f}$ and the MalE as well as to replace the native NADP-Icd ${ }_{C g}$ by NAD-Icd $_{C a}$ from S. mutans. In this study, the Gnd was not inactivated because the activity of Gnd was controlled by the availability of 6-phosphogluconate, which was the product in Zwf-catalyzed reaction (Fig. 1). In addition, the strain with the activated Gnd can maintain the cell growth during using gluconate as carbon source because gluconate can convert to 6-phosphogluconate without Zwf participation (Lindner et al. 2018). The cell growth of Zwf-deficient strain (i.e., $C$. glutamicum XL-1 $\Delta Z$ ) was significantly decreased during growth on most carbon source except on gluconate, whereas the cell growth of MalE-deficient strain (i.e., C. glutamicum XL-1 $\triangle \mathrm{M}$ ) had little change during growth on the test carbon sources except on succinate (Fig. 2a-c). It is worth noting that replacement of

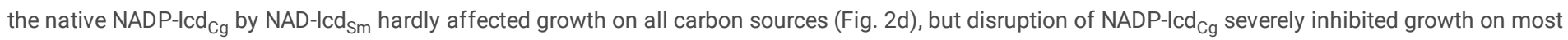
other carbon sources except on succinate (Fig. 2e). Next, we integrated the above gene modifications with the disruption of MalE and/or replacement with NAD-Icd $\mathrm{Sm}_{\mathrm{Sm}}$. As can be seen from Fig. 2b, $\mathrm{f}, \mathrm{g}$, further disruption of MalE in strain XL-1 $\Delta \mathrm{Z}$ was not significantly impaired cell growth on any of the carbon sources, but further replacement with NAD-Icd $\mathrm{Sm}_{\mathrm{m}}$ in strain XL-1 $\Delta \mathrm{Z}$ almost abolished cell growth on most carbon source except on gluconate. Deletion of $z w f$ and malE as well as replacement with icd ${ }_{\mathrm{Sm}}$ (i.e., C. glutamicum $\mathrm{XL}-1 \Delta \mathrm{ZMI} \mathrm{Cg}_{\mathrm{C}}: \mathrm{I}_{\mathrm{Sm}}$, also known as strain Leu-1) completely abolished cell growth on most carbon source except on gluconate (Fig. 2h). Different from the cell growth, the L-leucine yield of these recombinant strains was obviously decreased with modification of the enzyme involved in NADPH regeneration except the strain $C$. glutamicum $\mathrm{XL}-1 \Delta \mathrm{M}$ during cultivated in fermentation medium (Table 2). Thus, we selected strain Leu-1 as NADPH-auxotrophic C. glutamicum strain to optimize NADPH-supplying pathway for constructing L-leucine high-producing strain. 
Table 2

Cell weight, L-lecucine yield and content of intracellular pyridine nucleotides of recombinant and original strains in the fermentation medium

\begin{tabular}{|c|c|c|c|c|c|c|}
\hline C. glutamicum & $O D_{562}$ & L-leucine $^{a}$ & $\mathrm{NADPH}^{b}$ & $\mathrm{NADP}^{+} b$ & $\mathrm{NADH}^{b}$ & $\mathrm{NAD}^{+b}$ \\
\hline$X L-1$ & $39.5 \pm 2.7$ & $15.3 \pm 1.2$ & $3.74 \pm 0.35$ & $4.62 \pm 0.23$ & $4.27 \pm 0.43$ & $16.76 \pm 1.55$ \\
\hline $\mathrm{XL}-1 \Delta \mathrm{Z}$ & $27.2 \pm 1.8$ & ND & $0.93 \pm 0.10$ & $1.86 \pm 0.12$ & - & - \\
\hline $\mathrm{XL}-1 \Delta \mathrm{M}$ & $40.3 \pm 5.2$ & $14.5 \pm 1.6$ & $3.51 \pm 0.18$ & $4.67 \pm 0.47$ & - & - \\
\hline $\mathrm{XL}-1 \Delta \mathrm{I}_{\mathrm{Cg}} \cdot: \mathrm{I}_{\mathrm{Sm}}$ & $37.2 \pm 2.3$ & $8.6 \pm 1.5$ & $2.69 \pm 0.21$ & $4.54 \pm 0.26$ & - & - \\
\hline $\mathrm{XL}-1 \Delta \mathrm{Z} \Delta \mathrm{M}$ & $25.9 \pm 2.5$ & ND & $0.74 \pm 0.08$ & $1.65 \pm 0.21$ & - & - \\
\hline $\mathrm{XL}-1 \Delta \mathrm{Z} \Delta \mathrm{I}_{\mathrm{Cg}}: \mathrm{I}_{\mathrm{Sm}}$ & $3.5 \pm 0.2$ & ND & $0.07 \pm 0.01$ & $0.56 \pm 0.04$ & - & - \\
\hline Leu-1 & - & - & - & - & - & - \\
\hline Leu-2 & $34.6 \pm 3.2$ & $16.2 \pm 1.1$ & $4.48 \pm 0.34$ & $4.67 \pm 0.50$ & $2.23 \pm 0.24$ & $14.89 \pm 1.19$ \\
\hline $\mathrm{XL}-1 \mathrm{G}_{\mathrm{Cg}}:: \mathrm{G}_{\mathrm{Ca}}$ & $26.4 \pm 3.7$ & $14.1 \pm 1.8$ & $5.25 \pm 0.29$ & $4.33 \pm 0.27$ & $2.16 \pm 0.16$ & $14.78 \pm 1.26$ \\
\hline Leu-2/pEC-ABNCE & $40.7 \pm 3.4$ & $26.3 \pm 1.7$ & $3.06 \pm 0.17$ & $4.94 \pm 0.24$ & $2.75 \pm 0.25$ & $15.28 \pm 1.12$ \\
\hline Leu-2/pEC-ABNCM ${ }^{M}$ & $30.4 \pm 3.7$ & $22.6 \pm 2.3$ & $4.24 \pm 0.38$ & $4.76 \pm 0.43$ & $2.44 \pm 0.13$ & $14.35 \pm 1.43$ \\
\hline Leu-3 & $35.7 \pm 4.0$ & $24.8 \pm 2.7$ & $4.08 \pm 0.24$ & $4.61 \pm 0.31$ & $2.85 \pm 0.21$ & $15.01 \pm 1.62$ \\
\hline Leu-4 & $37.2 \pm 2.2$ & $28.6 \pm 2.4$ & $3.57 \pm 0.37$ & $4.63 \pm 0.19$ & $2.97 \pm 0.17$ & $14.85 \pm 0.87$ \\
\hline Leu-5 & $38.9 \pm 2.6$ & $26.9 \pm 2.1$ & $3.15 \pm 0.19$ & $4.79 \pm 0.36$ & $2.79 \pm 0.28$ & $15.23 \pm 1.70$ \\
\hline Leu-6 & $45.9 \pm 4.6$ & $24.2 \pm 2.2$ & $3.53 \pm 0.28$ & $4.65 \pm 0.42$ & $4.32 \pm 0.23$ & $16.62 \pm 1.02$ \\
\hline Leu-7 & $48.1 \pm 3.9$ & $23.6 \pm 2.4$ & $3.51 \pm 0.33$ & $4.65 \pm 0.35$ & $4.57 \pm 0.47$ & $16.32 \pm 1.43$ \\
\hline Leu-8 & $52.6 \pm 6.4$ & $22.3 \pm 1.3$ & $3.37 \pm 0.26$ & $4.48 \pm 0.29$ & $5.08 \pm 0.44$ & $16.93 \pm 1.71$ \\
\hline Leu-9 & $41.3 \pm 4.2$ & $32.8 \pm 1.7$ & $3.49 \pm 0.14$ & $4.56 \pm 0.13$ & $3.72 \pm 0.27$ & $16.39 \pm 1.09$ \\
\hline Leu-10 & $45.1 \pm 3.5$ & $30.5 \pm 2.6$ & $3.35 \pm 0.21$ & $4.45 \pm 0.11$ & $3.93 \pm 0.15$ & $16.38 \pm 1.32$ \\
\hline Leu-11 & $50.6 \pm 6.4$ & $28.7 \pm 3.2$ & $3.24 \pm 0.16$ & $4.44 \pm 0.23$ & $4.51 \pm 0.32$ & $16.70 \pm 1.53$ \\
\hline
\end{tabular}

\section{Replacement of glyceraldehyde 3-phosphate dehydrogenase to restore NADPH regeneration and L-leucine production}

As mentioned above, the strain Leu-1 is an NADPH-auxotrophic C. glutamicum strain, thus abolishing cell growth and L-leucine production on glucose (Fig. 2). In 2018, NADPH-auxotrophic E. coli strain was used as chassis cells to assess the capacity of different enzymes to biosynthesize NADPH (Lindner et al. 2018). In this study, we tried to use strain Leu-1 as chassis cells to investigate the effect of exogenous NADPH-supplying pathway on L-leucine production. Previous researchers indicated that replacing the native NAD-dependent glyceraldehyde-3-phosphate dehydrogenase (NAD-GapDH) with the nonphosphorylating NADP-GapDH allows cells to produce 2 molecules of NADPH rather than NADH per molecule of glucose (Martinez et al. 2008). Thus, we replaced the native NAD-GapDH with the NADP-GapDH from $C$. acetobutylicum in strain Leu-1, and the resultant strain $C$. glutamicum XL-1

$\triangle \mathrm{ZMI}_{\mathrm{Cg}}: \mathrm{I}_{\mathrm{Sm}} \mathrm{G}_{\mathrm{Cg}}:{ }_{\mathrm{G}} \mathrm{Ca}$ (i.e., strain Leu-2) restored the regenerative power of NADPH using glucose as carbon source (Table 2). As a control, we also replaced the NAD-GapDH $\mathrm{Cg}_{\text {gith }}$ NADP-GapDH $\mathrm{Ca}_{\text {in }}$ strain XL-1, and the resultant strain $C$. glutamicum XL-1 $\mathrm{G}_{\mathrm{Cg}}::_{\mathrm{Ca}}$ obviously increased the intracellular NADPH level (Table 2). In addition, The maximum specific growth rate $\left(\mu_{\max }\right)$ for the parental strain $X L-1$ and the GapDH modified strains Leu-2 and XL-1 $\mathrm{G}_{\mathrm{Cg}}: \mathrm{G}_{\mathrm{Ca}}$ were $0.35 \mathrm{~h}^{-1}, 0.32 \mathrm{~h}^{-1}$ and $0.19 \mathrm{~h}^{-1}$, respectively. And the final $\mathrm{OD}_{562}$ of these above strains are listed in Table 2. As expected, the strain Leu-2 produced $16.2 \pm 1.1$ $\mathrm{g} / \mathrm{L}$ of L-leucine because of the restoration of NADPH supply, which was slight higher than that of parental strain XL-1 (15.3 $\pm 1.2 \mathrm{~g} / \mathrm{L}$ of $\mathrm{L}-\mathrm{leucine}$ )(Fig. 3 ). It is worth noting that the productivity (i.e., the L-leucine yield per $\left.\mathrm{OD}_{562}\right)$ of strain Leu- 2 was obvious higher than that of strain $\mathrm{XL}-1\left\{0.468 \mathrm{vs} 0.387 \mathrm{~g} /\left(\mathrm{L} \cdot \mathrm{OD} \mathrm{D}_{562}\right)\right.$;

Fig. 3\}. In addition, strain $X L-1 G_{C g}:: G_{C a}$ only produced $14.1 \pm 1.8 \mathrm{~g} / \mathrm{L}$ of L-leucine (Fig. 3), even though the intracellular NADPH level in strain XL-1 $G_{C g}:: G_{C a}$ was higher than that in strain Leu-2 and strain XL-1 (Table 2). However, the productivity of strain $\mathrm{XL}-1 \mathrm{G}_{\mathrm{Cg}}: \mathrm{G}_{\mathrm{Ca}}$ was $0.534 \mathrm{~g} /(\mathrm{L} \cdot \mathrm{OD} 562)$, which was $14.1 \%$ and $40.0 \%$ higher than that of strain Leu-2 and strain XL-1, respectively (Fig. 3).

\section{Enhancing the carbon flux in L-leucine biosynthetic pathway to further promoting L- leucine production}

There are seven enzyme-catalyzed reactions from pyruvate in L-leucine biosynthetic pathway (Fig. 1). In order to enhance the carbon flux in L-leucine biosynthetic pathway, we tried to over-express the genes ilvBN (encoding acetohydroxyacid synthase, AHAS, represented by "BN"), ilvC (encoding AHAIR, represented by " $\mathrm{C}$ "), leuA (encoding a-isopropylmalate synthase, IPMS, represented by " $\mathrm{A}$ ") and ilvE (encoding BCAT, represented by " $\mathrm{E}$ ") by expression vector 


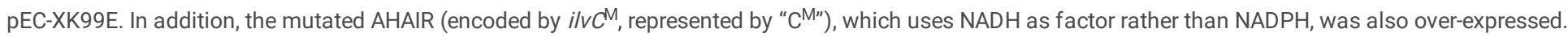
The resulted plasmids $p E C-A B N C E$ and $p E C-A B N C^{M} E$ was transferred into strain Leu-2, and the cell growth, L-leucine yield as well as the intracellular $\mathrm{NADH}$ and NADPH level in the resultant recombinant strains were determined. The resultant strain Leu-2/pEC-ABNCE showed the similar cell growth with the parental strain XL-1, whereas the resultant strain Leu-2/pEC-ABNC ${ }^{M} E$ obviously decreased the cell growth as compared with the parental strain XL-1 (Table 2). In addition, the intracellular NADPH level of strain Leu-2/pEC-ABNCE was decrease to $2.56 \times 10^{-4} \mathrm{nmol} /\left(10^{4}\right.$ cell), which was $64.3 \%$ lower than that of strain Leu2 (Table 2). However, the strain Leu-2/pEC-ABNCM E exhibited a slight decrease in the intracellular NADPH level as compared with the strain Leu-2 (Table 2). As expected, strain Leu-2/pEC-ABNCE produced $26.3 \pm 1.7 \mathrm{~g} / \mathrm{L}$ of L-leucine in 72 -h shake flask fermentation, which was about 1.6 and 1.2 times higher than that of strain Leu-2 $(16.2 \pm 1.1 \mathrm{~g} / \mathrm{L})$ and strain Leu-2/pEC-ABNC ${ }^{\mathrm{M}} \mathrm{E}(22.6 \pm 2.3 \mathrm{~g} / \mathrm{L})$, respectively (Fig. 3$)$. It is worth noting that strain Leu-2/pEC-ABNCM ${ }^{\mathrm{E}}$ showed

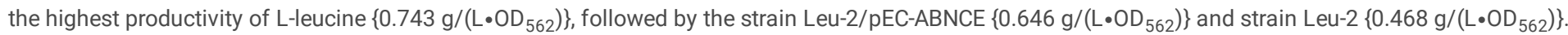

\section{Analyzing the promoter activity of key enzymes involved in NADPH regeneration to determine the key pathway for NADPH regeneration}

As mentioned above (Table 2, Fig. 3), strain Leu-2/pEC-ABNCM E showed the high intracellular NADPH level and L-leucine productivity despite of the low Lleucine yield. In contrast, strain Leu-2/pEC-ABNCE exhibited the low intracellular NADPH level and L-leucine productivity as well as the high L-leucine yield. We speculated that the L-leucine production in strain Leu-2/pEC-ABNCE was limited because of the shortage of NADPH. Thus, future research should focus on improving NADPH supply by optimizing the NADPH biosynthetic pathway. To determine the promoter activity of zwf, gnd, icd and malE in $C$. glutamicum XL-1, their upstream regions of these genes were cloned in the promoter-probe vector pDXW-11, giving rise to the constructs pDXW-11- $P_{z w f}, \mathrm{pDXW}-11-P_{\text {gnd }}, \mathrm{pDXW}-$ 11- $P_{\text {icd }}$ and pDXW-11- $P_{\text {malE }}$ (Fig. 4a). Based on the analysis results from BDGP (Berkeley Drosophila Genome Project,

https://www.fruitfly.org/seq_tools/promoter.html), BPROM (http://linux1.softberry.com/berry.phtml?topic=bprom\&group=programs\&subgroup=gfindb) and reported by Pátek and Nešvera (Miroslav Patek \& Nesvera, 2013), about 400 bp fragment upstream from initiation codon of these genes included all of promoter elements, and the potential -10 and -35 regions as well as the transcriptional start site are summarized in Table 3 . The transcriptional activity of these cloned fragments including promoters in C. glutamicum was investigated using the cat reporter gene (encoding CAT) in the extracts of cells cultivated in LBG medium. The CAT-coding gene in plasmid pDXW-11 was successfully expressed under the control of these mentioned promoters (Fig. 4b). As can be seen from Table 3 , in addition, the promoters $P_{\text {zwf }}$ and $P_{\text {gnd }}$ were strong $\{0.365 \pm 0.038 \mathrm{U} /(\mathrm{mg}$ protein) and $0.406 \pm 0.025 \mathrm{U} /(\mathrm{mg} \mathrm{protein})$, respectively\}, whereas the promoter $P_{\text {malE }}$ was rather weak $\left\{0.010 \pm 0.003 \mathrm{U} /(\mathrm{mg}\right.$ protein) $\}$ and the promoter $P_{\text {icd }}$ was of intermediate strength $\{0.092 \pm 0.012 \mathrm{U} /(\mathrm{mg}$ protein) $\}$. These results indicated that the PP pathway is the key pathway for NADPH regeneration and the tricarboxylic acid (TCA) cycle comes second, whereas the transhydrogenase-like cycle hardly works in strain XL-1.

Table 3

Activity of promoters assayed by measuring the specific activity of chloramphenicol acetyltransferase (CAT) in cell extracts of $C$. glutamicum

\begin{tabular}{|c|c|c|c|c|}
\hline Promoter & The key elements of promoter ${ }^{a}$ & -10 region $b$ & CAT (U/mg protein) & Upstream from $\mathrm{ORF}^{c}$ \\
\hline$P_{\mathrm{zwf}}^{d}$ & gacatgaaatcgaattagttcgatcttatgtggccg & tcttat & $0.365 \pm 0.038$ & $42 \mathrm{bp}$ \\
\hline$P_{\text {gnd }}{ }^{d}$ & ggattttcacctcctgtgacctggtaaaatcgccacta & taaaat & $0.406 \pm 0.025$ & $47 \mathrm{bp}$ \\
\hline$P_{\mathrm{malE}}{ }^{e}$ & ttttgttgagctacagatttagctagtgttttgttcca & $\operatorname{tg} t t t t$ & $0.010 \pm 0.003$ & $69 \mathrm{bp}$ \\
\hline$P_{\text {icd }}{ }^{e}$ & taggcgccagcaattagtagaacactgtattctaggtagctg & tattct & $0.092 \pm 0.012$ & $30 \mathrm{bp}$ \\
\hline$P_{\text {gapA }}{ }^{e}$ & tctgctgcgaaatctttgtttccccgctaaagttgaggac & taaagt & $0.753 \pm 0.023$ & $183 \mathrm{bp}$ \\
\hline$P_{\mathrm{zwf}}-\mathrm{D} 5$ & - & CctAat & $0.193 \pm 0.021$ & - \\
\hline$P_{\mathrm{zwf}}-\mathrm{D} 1$ & - & CcttaA & $0.106 \pm 0.005$ & - \\
\hline$P_{\mathrm{zwf}} \mathrm{S} 6$ & - & tcttaG & $0.035 \pm 0.008$ & - \\
\hline$P_{\text {icd }}{ }^{-T 3}$ & - & AatAAt & $0.179 \pm 0.016$ & - \\
\hline$P_{\text {icd }}-\mathrm{S} 7$ & - & tattAt & $0.285 \pm 0.032$ & - \\
\hline$P_{\text {icd }}-\mathrm{D} 2$ & - & tatAAt & $0.462 \pm 0.027$ & - \\
\hline \multicolumn{5}{|c|}{$\begin{array}{l}\text { a The bold and italic letters represent the }-35 \text { region, the letters with underline represent - } 10 \text { region and the bold letters with underline represent the } \\
\text { transcriptional start site. }\end{array}$} \\
\hline \multicolumn{5}{|c|}{${ }^{b}$ Nucleotide substitutions are capital letters and in bold. } \\
\hline \multicolumn{5}{|c|}{${ }^{c}$ It represents the distance between the transcriptional start site and the initiation codon. } \\
\hline \multicolumn{5}{|c|}{${ }^{d}$ The key elements of promoter were deduced from programs BDGP and BPROM. } \\
\hline
\end{tabular}

Constructing the mutant promoters of the zwf and/or icd $\mathrm{cg}$ genes to balance the intracellular NADPH and NADH level 
As the mention above (Fig. 3), although the strain Leu-2/pEC-ABNC ${ }^{M} E$ showed the lower L-leucine yield than that of strain Leu-2/pEC-ABNCE, it showed the higher productivity than that of strain Leu-2/pEC-ABNCE. These results implied that the strain Leu-2/pEC-ABNCME accumulates excess intracellular NADPH level but the strain Leu-2/pEC-ABNCE lacks adequate NADPH for L-leucine production. It should be noted that the promoter of $g a p A$ gene (i.e., $P_{\text {gapA }}$ ) is a strong promoter because the strain with pDXW-11- $P_{\text {gapA }}$ showed the high CAT activity $\{0.753 \pm 0.023 \mathrm{U} /$ (mg protein)\}(Table 3 ). In order to efficiently supply NADPH for L-leucine production, the promoters of the $z w f$ and/or $i c d_{\mathrm{Cg}}$ genes (i.e., $P_{\mathrm{zwf}}$ and $P_{\text {icd }}$ ) were mutated to regulate the expression level of genes controlled by these promoters. In this study, the -10 region of $P_{\text {zwf }}$ and $P_{\text {icd }}$ was selected as modified object to regulate promoter activity, and the promoter activity was analyzed the CAT activity using the promoter-probe vector pDXW-11. As can be seen from Table 3 and Figure S2, the mutated promoters with base substitution in conservative positions of -10 regions showed the low activity, whereas base substitution in nonconservative positions showed the positive effects on increasing promoter activity. For optimizing promoter of gene $z w f$, the mutated promoters $P_{\mathrm{zwf}}$-D5, $P_{\mathrm{zwf}}$-D1 and $P_{\mathrm{zwf}}$-S6 (with about $50 \%, 30 \%$ and $10 \%$ of activity of native-type $P_{\text {zwf }}$, respectively) were selected for further investigating. In addition, the mutated promoters $P_{\text {icd }}{ }^{-T 3}, P_{\text {icd }}-\mathrm{S} 7$ and $P_{\text {icd }}$-D2 (with about 2.0-, 3.0- and 5.0-fold stronger than native-type $P_{\text {icd, }}$, respectively) were selected for optimizing promoter of gene icd.

Following, the mutated $P_{\mathrm{zwf}}$ were introduced into strain Leu-2 to control the expression of $z w f$ gene, and the mutated $P_{\text {icd }}$ replaced the native promoter of $i c d_{\mathrm{Cg}}$ gene in strain Leu-2 to control the expression of $i c d_{S m}$ gene. Subsequently, the overexpression plasmid pEC-ABNCE was transferred into these recombinant strains. The resultant strains with the mutated $P_{\text {zwf }}$ \{i.e., $C$. glutamicum Leu-2 $P_{\mathrm{zwf}}$-D5/pEC-ABNCE (strain Leu-3), C. g/utamicum Leu-2 $P_{\mathrm{zwf}}$-D1/pEC-ABNCE (strain Leu-4) and C. glutamicum Leu-2 $P_{\mathrm{zwf}} \mathrm{S} 6 / \mathrm{pEC}-\mathrm{ABNCE}$ (strain Leu-5)\} showed the increased yield and productive of L-leucine as compared with the strain Leu-2 (Fig. 5a). Among them, the strain Leu-4 showed the best fermentation performance, which produced $28.6 \pm 2.4 \mathrm{~g} / \mathrm{L}$ of L-leucine with a productivity of

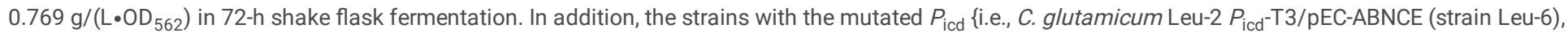
C. glutamicum Leu-2 $P_{\text {icd }}$-S7/pEC-ABNCE (strain Leu-7) and $C$. glutamicum Leu-2 $P_{\text {icd }}$-D2/pEC-ABNCE (strain Leu-8)\} exhibited a 5-20\% decrease in L-leucine production and a 10-30\% increase in cell growth (Table 2). However, replacement of the native $P_{\text {icd }}$ by the $P_{\text {icd }}{ }^{-T} 3$ in the strain Leu-4 showed the best L-leucine yield and cell growth (Fig. 5a). The resultant strain C. glutamicum Leu-2 $P_{\mathrm{zwf}}-\mathrm{D} 1 P_{\text {icd }}$-T3/pEC-ABNCE (i.e., strain Leu-9) produced $32.8 \pm 1.7 \mathrm{~g} / \mathrm{L}$ of L-leucine and its $\mathrm{OD}_{562}$ reached to $41.3 \pm 4.2$ during cultivated in shake flask for $72 \mathrm{~h}$. In addition, the strain Leu-9 has been a slight increase in the intracellular NADH level and the ratio of $\mathrm{NADH} / \mathrm{NAD}^{+}$(Table 2). However, introduction of the strong promoters $P_{\text {icd }}{ }^{-S 7}$ and $P_{\text {icd }}$-D2 to control icd ${ }_{\text {Sm }}$ gene expression (i.e., strain Leu-10 and Leu-11) was harmful to L-leucine production despite increasing the cell growth and the intracellular NADH level (Fig. 5b, Table 2). Therefore, we speculated that the strain Leu-9 with $P_{\mathrm{zwf}}-\mathrm{D} 1$ and $P_{\text {icd }}$-T3 to respectively control the expression of $z w f$ and $i c d_{\text {Sm }}$ exhibited the proper intracellular NADPH and $\mathrm{NADH}$ level, and thus beneficial to L-leucine production.

\section{Discussion}

For the first time, we report an NADPH-auxotrophic $C$. glutamicum recombinant strain and use it to construct L-leucine high-yielding strain. To do this, an Lleucine-producing strain C. glutamicum XL-1 was consecutively modified to give strain XL-1 with high-efficiency of L-leucine production, for example, deletion of the native promoter of the NADPH-regenerating enzymes-coding genes to construct a $C$. glutamicum NADPH-auxotroph strain, introduction of the nonphosphorylating NADP-GapDH to restore NADPH regeneration and optimization of the promoters of the $z w f$ and/or $i c d_{C g}$ genes to balance the intracellular NADPH and NADH level. As a result, a L-leucine high-producing strain C. glutamicum Leu-9 was obtained, which produced $32.8 \pm 1.7 \mathrm{~g} / \mathrm{L}$ of L-leucine with a productivity of $0.794 \mathrm{~g} /\left(\mathrm{L} \cdot \mathrm{OD}_{562}\right)$ in 72 -h shake flask fermentation. These results are encouraging, as far as we know (Table 4$)$, indicating that strain Leu-9 is a competitive platform strain for L-leucine production. These results also inferred that optimization of the biosynthetic pathway of NADPH from an NADPHauxotrophic strain is easy to reasonably supply NADPH, thus increasing the production of NADPH-dependent valuable chemicals.

Table 4

Overview of the production of L-leucine by metabolic engineered C. glutamicum

\begin{tabular}{|c|c|c|c|c|c|}
\hline C. glutamicum strains & Fermentation mode & Fermentation time & $\begin{array}{l}\text { Final titers } \\
(\mathrm{g} / \mathrm{L})\end{array}$ & Productivity $\left(g /\left(L \cdot O D_{562}\right)\right)$ & Reference \\
\hline Leu-9 & Shake-flask & $72 \mathrm{~h}$ & 32.8 & 0.794 & This work \\
\hline $\mathrm{CP}$ & Ultrasound-assisted fed-batch & $44 \mathrm{~h}$ & 52.89 & $0.425^{a}$ & (Zhang et al., 2021a) \\
\hline $\mathrm{CP}$ & Fed-batch & $44 \mathrm{~h}$ & 53.0 & $0.504^{a}$ & (Zhang et al., 2021b) \\
\hline WL-14 & Shake-flask & $72 \mathrm{~h}$ & 28.47 & $0.811^{a}$ & (Wang et al., 2020) \\
\hline Leu14 & Shake-flask & $72 \mathrm{~h}$ & 14.05 & $0.502^{a}$ & (Luo et al., 2021) \\
\hline MV-LeuF2 & Fed-batch & $56 \mathrm{~h}$ & 23.7 & $-b$ & (Vogt et al., 2014) \\
\hline
\end{tabular}

${ }^{a}$ Estimated from reference. The relation between DCW and OD562 was referred to the formula: $\mathrm{DCW}(\mathrm{g} / \mathrm{L})=0.57 \times 0 \mathrm{D}_{562}+0.23$ reported in previous study (Wang et al., 2020).

${ }^{b}$ No computed data.

In C. glutamicum, there are four enzymes involved in NADPH biosynthesis, i.e., Zwf, Gnd, NADP-Icd and MalE (Fig. 1) (Hoffmann et al. 2021; Xu et al. 2019). It is clear from this study of the roles of NADPH-regenerating enzymes that different NADPH-regenerating enzymes show a huge difference in catalyzing the NADPH regeneration in C. glutamicum (Table 2 and Fig. 2). As previous reports (Lindner et al. 2018), our results show that Zwf and Gnd in PP pathway are the 
main enzymes for NADPH regeneration, in which the promoters $P_{\text {zwf }}$ and $P_{\text {gnd }}$ from strain XL-1 show the strong activity (Table 3 ). It is worth noting that the native $P_{\text {icd }}$ from strain XL-1 show the weak activity (Table 3), which is different from previous reports (Aich et al. 2001; Han et al. 2008). Han et al. pointed out that the transcript level of icd from C. glutamicum R is high (i.e., $10 \sim 25$ ) in the presence of most of carbon sources, except citrate, succinate and malate (Han et al. 2008). In addition, Aich et al. agreed that the icd promoter from E. coli is a strong promoter (Aich et al., 2001). Previous studies have already indicated that the activity of icd promoter is regulated by secondary substances and accessory proteins (Prost et al. 1999; Shechter et al. 2003). Moreover, base mutation in promoter including - 10 region, -35 region and upstream of -35 region will lead to change the promoter activity (Holatko et al. 2009 ; Vasicova et al. 1999). Given that the strain XL-1 is mutant strain engineered by repeated random mutagenesis (Wang et al. 2019b), random genetic mutation may be happen in some structure genes and/or icd promoter and furthermore changes the amount of secondary substances and accessory proteins as well as promoter activity. As expected, inactivation of these NADPH-regenerating enzymes in $C$. glutamicum leads to no NADPH biosynthesis in the resultant strain Leu- 1 except using gluconate as carbon source (Table 2 and Fig. 2). The similar results are also found in previous research, in which the NADPH-auxotroph strain E. coli NADPHaux grew well only using gluconate as carbon source (Lindner et al. 2018).

Biosynthesis of 1 molecule of L-leucine needs 2 molecules of NADPH (Wang et al. 2019b). To meet the requirement of NADPH for L-leucine production, the native NAD-GapDH was replaced by the NADP-GapDH in strain Leu-1 and original strain XL-1. Since NADP-GapDH allows cells to produce 2 molecules of $\mathrm{NADPH}$ per molecule of glucose (Martinez et al. 2008), the resultant strain Leu-2 restored the cell growth and L-leucine production using glucose as carbon source (Table 2, Fig. 3). However, the L-leucine productivity of strain XL-1 $\mathrm{G}_{\mathrm{Cg}}: \mathrm{G}_{\mathrm{Ca}}$ was higher than that of strain Leu-2 and strain XL-1, even though the Lleucine yield of strain $X L-1 G_{C g}:: G_{C a}$ was lower than that of strain Leu-2 and strain XL-1 (Table 2, Fig. 3). In addition, the strain Leu-2 showed the lower the cell growth than that of strain XL-1 despite the higher L-leucine production (Table 2). We speculate that the NADPH supply is inadequate to meet the requirement of NADPH for L-leucine production in strain XL-1, whereas strain Leu-2 and strain XL-1 $\mathrm{G}_{\mathrm{Cg}}:: \mathrm{G}_{\mathrm{Ca}}$ accumulates excess $\mathrm{NADPH}$ and thus to limit the cell growth. This speculation has been proved during enhancement of the carbon flux in L-leucine biosynthetic pathway in strain Leu-2. As can be seen from Table 2, strain Leu-2/pEC-ABNCE showed the similar cell growth with the parental strain XL-1 and the higher than that of strain Leu-2. By contrast, the resultant strain Leu2/pEC-ABNC ${ }^{M}$ ebviously decreased the cell growth as compared with the parental strain XL-1 (Table 2). The difference between pEC-ABNCE and pEC$A B N C^{M} E$ is the AHAIR-coding gene ilvC that needs NADPH as cofactor to catalyze the biosynthesis of a, $\beta$-dihydroxyisovalerate. However, the mutated AHAIR (encoded by gene $i / v C^{\mathrm{M}}$, abbreviated to $C^{\mathrm{M}}$ ) uses NAD as cofactor to catalyze the biosynthesis of a, $\beta$-dihydroxyisovalerate because of the mutant AHAIR with three amino acid mutations (i.e., S34G, L48E, and R49F) (Hasegawa et al. 2013). As a result, the intracellular NADPH level of strain Leu-2/pEC-ABNCME was slightly decreased while that of strain Leu-2/pEC-ABNCE was significantly decreased (Table 2). Although strain Leu-2/pEC-ABNCE produced more L-leucine titer than strain Leu-2/pEC-ABNC ${ }^{\mathrm{M}} \mathrm{E}(26.3 \pm 1.7 \mathrm{~g} / \mathrm{L}$ v.s. $22.6 \pm 2.3 \mathrm{~g} / \mathrm{L})$, but the productivity of L-leucine was lower than that of strain Leu-2/pEC-ABNCME $\left\{0.646 \mathrm{~g} /\left(\mathrm{L} \cdot \mathrm{OD}_{562}\right)\right.$ v.s. $\left.0.743 \mathrm{~g} /\left(\mathrm{L} \cdot \mathrm{OD}_{562}\right)\right\}$. The results demonstrated that the NADPH supply in strain Leu-2/pEC-ABNCE is still limiting factor for $\mathrm{L}$-leucine production. In order to increase NADPH supply in strain Leu-2/pEC-ABNCE, the key enzymes in NADPH regeneration (i.e., Zwf and Icd) were reasonably modified again. To do this, the -10 region in promoters of the $z w f$ and/or $i c d_{\mathrm{cg}}$ genes (i.e., $P_{\mathrm{zwf}}$ and $P_{\text {icd }}$ ) were mutated to regulate the expression level of $z w f$ and $i c d_{\mathrm{Cg}}$. Consistent with the previous results (Holatko et al. 2009; Vasicova et al. 1999), the mutated promoters with base substitution in conservative positions of -10 regions showed the low activity, whereas base substitution in nonconservative positions showed the positive effects on increasing promoter activity (Table 3 and Figure S2). To optimize the expression level of $z w f$ and $i c d_{\mathrm{Cg}}$ for balance the intracellular NADPH and NADH level, three mutated promoters of $P_{\mathrm{zwf}}$ (i.e., $P_{\mathrm{zwf}} \mathrm{D} 5, P_{\mathrm{zwf}}$ D1 and $P_{\mathrm{zwf}} \mathrm{S} 6$ ) and three mutated promoters of $P_{\text {icd }}$ (i.e., $P_{\text {icd }}{ }^{-\mathrm{T}}$ 3, $P_{\text {icd }}$-S7 and $P_{\text {icd }}{ }^{-\mathrm{D} 2)}$ were selected for further investigating the effect on L-leucine production. As can be seen from Table 2, the intracellular NADPH level was decreased with the decrease of promoter activity of $P_{\mathrm{zwf}}$, whereas the highest L-leucine yield (i.e., $28.6 \pm 2.4 \mathrm{~g} / \mathrm{L}$ ) was found in strain Leu-4 with $P_{\mathrm{zwf}}$ D1. These results indicated that excess NADPH supply is bad for L-leucine production. The similar results were also found in previous reports, in which excess NADPH supply will disturbs glucose uptake and cell growth and thus to inhibit the production of L-lysine or L-threonine (Liu et al. 2019; Xu et al. 2019). It is worth noting that the L-leucine yield was not increased but the cell growth was obviously increased during increasing the promoter activity of $P_{\text {icd }}$ (Table 2). The similar results were also found in the next study that the mutated $P_{\text {icd }}$ with different activity were introduced in the strain Leu-4 (Table 2 and Fig. 5a). One of the reasons is that more NADH was regenerated during increase of the activity of $\mathrm{Icd}_{\mathrm{Sm}}$ (Table 2 and Fig. 5b), and thus to meet the demand of cell growth for energy (Yumnam et al., 2021). It should be noted that the strains with high $\mathrm{Icd}_{\mathrm{Sm}}$ activity showed the low yield and productivity of L-leucine because more carbon source was used for cell growth.

In conclusion, an NADPH-auxotrophic $C$. glutamicum recombinant strain can be constructed by inactivation of Zwf and MalE as well as replacement of icd $\mathrm{Cg}$ by $i c d_{\mathrm{Sm}}$ in $C$. glutamicum. The NADPH-auxotrophic $C$. glutamicum strain Leu-1 can be used as chassis cells for constructing L-leucine high-yielding strain based on optimizing the biosynthetic pathway of NADPH. After a series of genetic modifications in strain Leu- 1 , an L-leucine high-yielding strain Leu-9 was obtained, which produced $32.8 \pm 1.7 \mathrm{~g} / \mathrm{L}$ of L-leucine with a productivity of $0.794 \mathrm{~g} /\left(\mathrm{L} \cdot \mathrm{OD}_{562}\right)$ in 72 -h shake flask fermentation.

\section{Abbreviations}

Zwf, glucose-6-phosphate dehydrogenase; MaIE, and malic enzyme; Icd, isocitrate dehydrogenase; GapDH, glyceraldehyde 3-phosphate dehydrogenase; AHAIR, acetohydroxyacid isomeroreductase; BCAT, branched-chain amino acid transaminase; Gnd, 6-phosphogluconate dehydrogenase; CAT, chloramphenicol acetyltransferase; ROS, reactive oxygen species.

\section{Declarations}

\section{Acknowledgments}


The authors would like to acknowledge Prof. Xiaoyuan Wang for plasmids pDXW-11 from State Key Laboratory of food Science and Technology in Jiangnan University. This work was financially supported by the National Key Research and Development Program of China (2021YFC2100900), the Key Laboratory of Industrial Biotechnology, Ministry of Education, Jiangnan University (KLIB-KF 202004), and Fundamental Research Funds for the Central Universities [No.

JUSRP115A19].

\section{Data availability}

Please contact author for data requests.

\section{Funding}

This work was financially supported by the National Key Research and Development Program of China (2021YFC2100900), the Key Laboratory of Industrial Biı KF 202004), and Fundamental Research Funds for the Central Universities [No. JUSRP115A19].

\section{Author information}

Affiliations

The Key Laboratory of Industrial Biotechnology, Ministry of Education, Ministry of Education, School of Biotechnology, Jiangnan University, 1800\# Lihu Road, WuXi 214122, People's Republic of China.

Contributions

Sheng-Ling Chen designed the research. Sheng-Ling Chen and Ting-Shan Liu performed the experiments, analyzed the data, and prepared the figures. ShengLing Chen, Ting-Shan Liu, and Jian-Zhong Xu wrote the manuscript.

Corresponding author

Correspondence to Jian-Zhong Xu.

\section{Ethics declarations}

\section{Conflicts of interest}

There are no conflicts to declare.

\section{Supporting Information}

The oligonucleotides used in this study; Strategy used for the construction of the integrative plasmids used for promoter deletion and gene replacement; Effects of mutations in the -10 region of $P_{\text {zwf }}(a)$ and $P_{\text {icd }}($ b) on promoter activity.

\section{References}

1. Aich S, Delbaere LTJ, Chen RD (2001) Expression and purification of Escherichia coli beta-glucuronidase. Protein Expr Purif 22(1):75-81. doi: 10.1006/prep.2001.1401

2. Calzadiaz-Ramirez L, Calvo-Tusell C, Stoffel GMM, Lindner SN, Osuna S, Erb TJ, Garcia-Borras M, Bar-Even A, Acevedo-Rocha CG (2020) In vivo selection for formate dehydrogenases with high efficiency and specificity toward NADP. ACS Catal 10(14):7512-7525. doi: 10.1021/acscatal.0c01487

3. Cardinali-Rezende J, Di Genova A, Nahat RATPS, Steinbuchel A, Sagot MF, Costa RS, Oliveira HC, Taciro MK, Silva LF, Gomez JGC (2020) The relevance of enzyme specificity for coenzymes and the presence of 6-phosphogluconate dehydrogenase for polyhydroxyalkanoates production in the metabolism of Pseudomonas sp. LFM046. Int J Biol Macromol 163:240-250. doi: 10.1016/j.ijbiomac.2020.06.226

4. Faijes M, Mars AE, Smid EJ (2007) Comparison of quenching and extraction methodologies for metabolome analysis of Lactobacillus plantarum. Microb Cell Fact 6:27. doi: 10.1186/1475-2859-6-27

5. Feng LY, Xu JZ, Zhang WG (2018) Improved L-leucine production in Corynebacterium glutamicum by optimizing the aminotransferases. Molecules 23(9):2102. doi: 10.3390/molecules23092102

6. Han SO, Inui M, Yukawa H (2008) Effect of carbon source availability and growth phase on expression of Corynebacterium glutamicum genes involved in the tricarboxylic acid cycle and glyoxylate bypass. Microbiology-SGM 154(10):3073-3083. doi: 10.1099/mic.0.2008/019828-0

7. Hasegawa S, Suda M, Uematsu K, Natsuma Y, Hiraga K, Jojima T, Inui M, Yukawa H (2013) Engineering of Corynebacterium glutamicum for high-yield Lvaline production under oxygen deprivation conditions. Appl Environ Microbiol 79(4):1250-1257. doi: 10.1128/AEM.02806-12

8. Hoffmann SL, Kohlstedt M, Jungmann L, Hutter M, Poblete-Castro I, Becker J, Wittmann C (2021) Cascaded valorization of brown seaweed to produce Llysine and value-added products using Corynebacterium glutamicum streamlined by systems metabolic engineering. Metab Eng 67:293-307. doi: 10.1016/j.ymben.2021.07.010

9. Holatko J, Elisakova V, Prouza M, Sobotka M, Nesvera J, Patek M (2009) Metabolic engineering of the L-valine biosynthesis pathway in Corynebacterium glutamicum using promoter activity modulation. J Biotechnol 139(3):203-210. doi: 10.1016/j.jbiotec.2008.12.005 
10. Horl M, Fuhrer T, Zamboni N (2021) Bifunctional malic/malolactic enzyme provides a novel mechanism for NADPH-balancing in Bacillus subtilis. mBio 12(2):e03438-e03420. doi: 10.1128/mBio.03438-20

11. Jiang LY, Zhang YY, Li Z, Liu JZ (2013) Metabolic engineering of Corynebacterium glutamicum for increasing the production of L-ornithine by increasing NADPH availability. J Ind Microbiol Biotechnol 40(10):1143-1151. doi: 10.1007/s10295-013-1306-2

12. Keilhauer C, Eggeling L, Sahm H (1993) Isoleucine synthesis in Corynebacterium glutamicum - Molecular analysis of the ilvB-ilvN-ilvC operon. J Bacteriol 175(17):5595-5603. doi: 10.1128/jb.175.17.5595-5603.1993

13. Li Y, Cong H, Liu BN, Song JZ, Sun XY, Zhang JZ, Yang Q (2016) Metabolic engineering of Corynebacterium glutamicum for methionine production by removing feedback inhibition and increasing NADPH level. Antonie Van Leeuwenhoek 109(9):1185-1197. doi: 10.1007/s10482-016-0719-0

14. Lindner SN, Ramirez LC, Krusemann JL, Yishai O, Belkhelfa S, He H, Bouzon M, Doring V, Bar-Even A (2018) NADPH-auxotrophic E. coli: A sensor strain for testing in vivo regeneration of NADPH. ACS Synth Biol 7(12):2742-2749. doi: 10.1021/acssynbio.8b00313

15. Liu J, Li H, Xiong H, Xie X, Chen N, Zhao G, Caiyin Q, Zhu H, Qiao J (2019) Two-stage carbon distribution and cofactor generation for improving I-threonine production of Escherichia coli. Biotechnol Bioeng 116(1):110-120. doi: 10.1002/bit.26844

16. Liu N, Zhang TT, Rao ZM, Zhang WG, Xu JZ (2021) Reconstruction of the diaminopimelic acid pathway to promote L-lysine production in Corynebacterium glutamicum. Int J Mol Sci 22(16):9065. doi: 10.3390/ijms22169065

17. Luo G, Zhao N, Jiang S, Zheng S (2021) Application of RecET-Cre/loxP system in Corynebacterium glutamicum ATCC14067 for L-leucine production. Biotechnol Lett 43(1):297-306. doi: 10.1007/s10529-020-03000-1

18. Ma C, Teng L, Lin G, Guo B, Zhuo R, Qian X, Guan T, Wu R, Liu Y, Liu M (2021) L-leucine promotes axonal outgrowth and regeneration via mTOR activation. FASEB J 35(5):e21526. doi: 10.1096/fj.202001798RR

19. Martinez I, Zhu JF, Lin H, Bennett GN, San KY (2008) Replacing Escherichia coli NAD-dependent glyceraldehyde 3-phosphate dehydrogenase (GAPDH) with a NADP-dependent enzyme from Clostridium acetobutylicum facilitates NADPH dependent pathways. Metab Eng 10(6):352-359. doi: 10.1016/j.ymben.2008.09.001

20. Miroslav P, Nesvera J (2013) Promoters and plasmid vectors of Corynebacterium glutamicum. In: Yukawa H, Inui M (eds) Corynebacterium glutamicum: biology and biotechonology. Springer, Verlag Beilin Heidelberg, pp 51-88

21. Prost JF, Negre D, Oudot C, Murakami K, Ishihama A, Cozzone AJ, Cortay JC (1999) Cra-dependent transcriptional activation of the icd gene of Escherichia coli. J Bacteriol 181(3):893-898. doi: 10.1128/JB.181.3.893-898.1999

22. Shechter I, Dai PH, Huo LA, Guan GM (2003) IDH1 gene transcription is sterol regulated and activated by SREBP-1a and SREBP-2 in human hepatoma HepG2 cells: evidence that IDH1 may regulate lipogenesis in hepatic cells. J Lipid Res 44(11):2169-2180. doi: 10.1194/jlr.M300285-JLR200

23. Tran KN, Jang SH, Lee C (2021) Effect of active-site aromatic residues Tyr or Phe on activity and stability of glucose 6-phosphate dehydrogenase from psychrophilic Arctic bacterium Sphingomonas sp. Biochim Biophys Acta Proteins Proteom 1869(1):140543. doi: 10.1016/j.bbapap.2020.140543

24. van der Rest ME, Lange C, Molenaar D (1999) A heat shock following electroporation induces highly efficient transformation of Corynebacterium glutamicum with xenogeneic plasmid DNA. Appl Microbiol Biotechnol 52(4):541-545. doi: 10.1007/s002530051557

25. Vasicova P, Patek M, Nesvera J, Sahm H, Eikmanns B (1999) Analysis of the Corynebacterium glutamicum dapA promoter. J Bacteriol 181(19):61886191. doi: 10.1128/JB.181.19.6188-6191.1999

26. Vogt M, Haas S, Klaff S, Polen T, Eggeling L, van Ooyen J, Bott M (2014) Pushing product formation to its limit: Metabolic engineering of Corynebacterium glutamicum for L-leucine overproduction. Metab Eng 22:40-52. doi: 10.1016/j.ymben.2013.12.001

27. Wang N, Zhang X, Liu C, Wang X, Zhou H, Mai K, He G (2021) Fine-tuning of postprandial responses via feeding frequency and leucine supplementation affects dietary performance in turbot (Scophthalmus maximus L.). J Nutr 151(10):2957-2966. doi: 10.1093/jn/nxab221

28. Wang P, Lv C, Zhu G (2015) Novel type II and monomeric NAD ${ }^{+}$specific isocitrate dehydrogenases: phylogenetic affinity, enzymatic characterization, and evolutionary implication. Sci Rep 5:9150. doi: 10.1038/srep09150

29. Wang YY, Shi K, Chen P, Zhang F, Xu JZ, Zhang WG (2020) Rational modification of the carbon metabolism of Corynebacterium glutamicum to enhance Lleucine production. J Ind Microbiol Biotechnol 47(6-7):485-495

30. Wang YY, Xu JZ, Zhang WG (2019a) Metabolic engineering of L-leucine production in Escherichia coli and Corynebacterium glutamicum: A review. Crit Rev Biotechnol 39(5):633-647. doi: 10.1080/07388551.2019.1577214

31. Wang YY, Zhang F, Xu JZ, Zhang WG, Chen XL, Liu LM (2019b) Improvement of L-leucine production in Corynebacterium glutamicum by altering the redox flux. Int J Mol Sci 20(8):2020. doi: 10.3390/ijms20082020

32. Xu DQ, Tan YZ, Li Y, Wang XY (2011) Construction of a novel promoter-probe vector and its application for screening strong promoter for Brevibacterium flavum metabolic engineering. World J Microbiol Biotechnol 27:961-968. doi: 10.1007/s11274-010-0539-8

33. Xu J, Han M, Ren X, Zhang W (2016) Modification of aspartokinase III and dihydrodipicolinate synthetase increases the production of L-lysine in Escherichia coli. Biochem Eng J 114:79-86. doi: 10.1016/j.bej.2016.06.025

34. Xu JZ, Han M, Zhang JL, Guo YF, Zhang WG (2014) Metabolic engineering Corynebacterium glutamicum for the L-lysine production by increasing the flux into L-lysine biosynthetic pathway. Amino Acids 46(9):2165-2175. doi: 10.1007/s00726-014-1768-1

35. Xu JZ, Ruan HZ, Chen XL, Zhang F, Zhang WG (2019) Equilibrium of the intracellular redox state for improving cell growth and L-lysine yield of Corynebacterium glutamicum by optimal cofactor swapping. Microb Cell Fact 18(1):65. doi: 10.1186/s12934-019-1114-0

36. Xu JZ, Yang HK, Zhang WG (2018) NADPH metabolism: a survey of its theoretical characteristics and manipulation strategies in amino acid biosynthesis. Crit Rev Biotechnol 38(7):1061-1076. doi: 10.1080/07388551.2018.1437387 
37. Yuan XS, Mao YD, Tu S, Lin JP, Shen HH, Yang LR, Wu MB (2021) Increasing NADPH availability for xylitol production via pentose-phosphate-pathway gene overexpression and embden-meyerhof-parnas-pathway gene deletion in Escherichia coli. J Agric Food Chem 69(33):9625-9631. doi: $10.1021 /$ acs.jafc. 1 c03283

38. Yumnam S, Kang MC, Oh SH, Kwon HC, Kim JC, Jung ES, Lee CH, Lee AY, Hwang Jl, Kim SY (2021) Downregulation of dihydrolipoyl dehydrogenase by UVA suppresses melanoma progression via triggering oxidative stress and altering energy metabolism. Free Radic Biol Med 162:77-87. doi: 10.1016/j.freeradbiomed.2020.11.037

39. Zhang Y, Chen Z, Sun P, Xu Q, Chen N (2021a) Effect of low-level ultrasound treatment on the production of L-leucine by Corynebacterium glutamicum in fed-batch culture. Bioengineered 12(1):1078-1090. doi: 10.1080/21655979.2021.1906028

40. Zhang Y, Xiong H, Chen Z, Fu Y, Xu Q, Chen N (2021b) Effect of fed-batch and chemostat cultivation processes of $C$. glutamicum CP for L-leucine production. Bioengineered 12(1):426-439. doi: 10.1080/21655979.2021.1874693

41. Zhu X, Guo Y, Liu Z, Yang J, Tang H, Wang Y (2021) Itaconic acid exerts anti-inflammatory and antibacterial effects via promoting pentose phosphate pathway to produce ROS. Sci Rep 11(1):18173. doi: 10.1038/s41598-021-97352-x

\section{Figures}

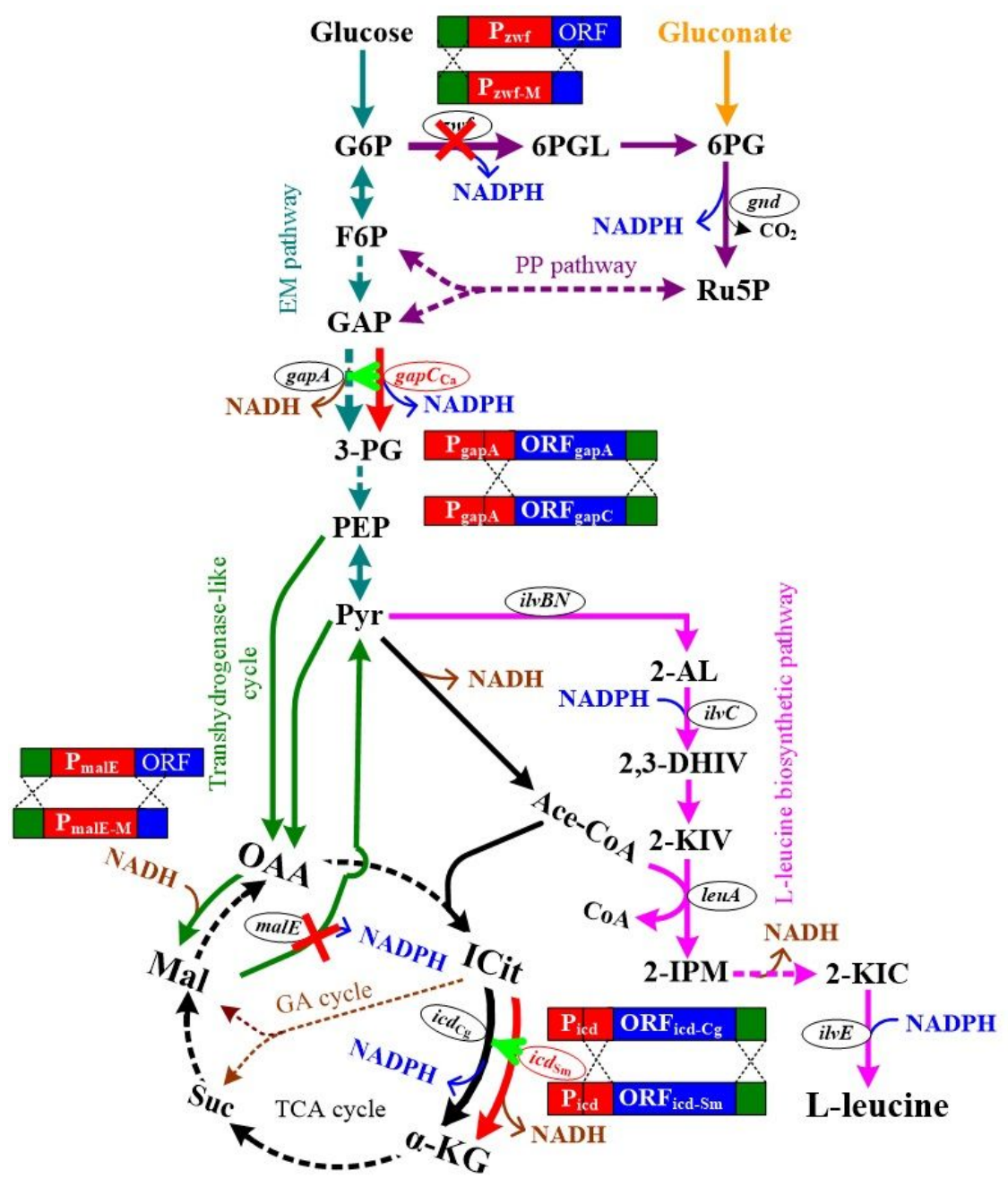

Figure 1

Schematic representation of the NADPH auxotrophic $\boldsymbol{C}$. glutamicum and modified strategies. NADPH and NADH metabolic pathway are shown in blue arrows and brown arrows, respectively. The red arrows represent the extrinsic routes. The symbols and represent the deletion and the replacement, respectively. Abbreviations: G6P, glucose-6-phosphate; 6PGL, 6-phosphogluconolactone; 6PG, 6-phosphogluconate; Ru5P, ribulose-5-phosphate; F6P, fructose-6-phosphate; GAP, glyceraldehyde-3-phosphate; 3-PG, 3-phosophoglycerate; PEP, phosphoenolpyruvate; Pyr, pyruvate; Ace-CoA, acetyl-CoA; ICit, isocitrate; a-KG, aketoglutarate; Suc, succinate; Mal, malate; OAA, oxaloacetate; 2-AL, a-acetolactate; 2,3-DHIV, a, $\beta$-dihydroxyisovalerate; 2-KIV, a-ketoisovalerate; 2-IPM, aisopropylmate; 2-KIC, a-ketoisocaproate. 

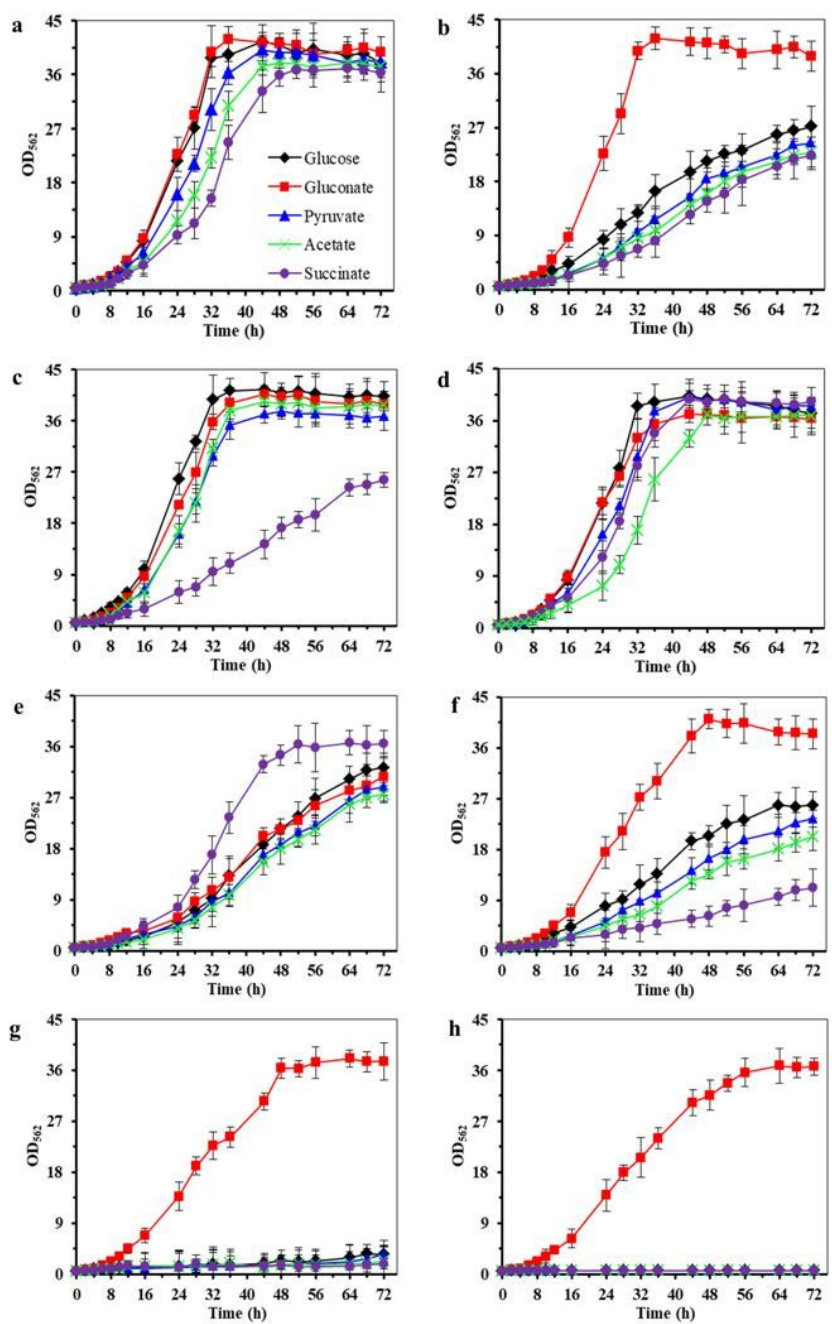

Figure 2

Growth phenotypes of recombinant and original strains under the different carbon sources. Figures from "a" to " $\mathrm{h}$ " represent strain $\mathrm{XL}-1, \mathrm{XL}-1 \Delta \mathrm{Z}, \mathrm{XL}-1 \Delta \mathrm{M}, \mathrm{XL}$ $1 \Delta \mathrm{I}_{\mathrm{Cg}}: \mathrm{I}_{\mathrm{Sm}}, \mathrm{XL}-1 \Delta \mathrm{I}_{\mathrm{Cg}}, \mathrm{XL}-1 \Delta \mathrm{Z} \Delta \mathrm{M}, \mathrm{XL}-1 \Delta \mathrm{Z} \Delta \mathrm{I}_{\mathrm{Cg}}: \mathrm{I}_{\mathrm{Sm}}$ and Leu-1, respectively. The data represent mean values and standard deviations obtained from three independent cultivations. 


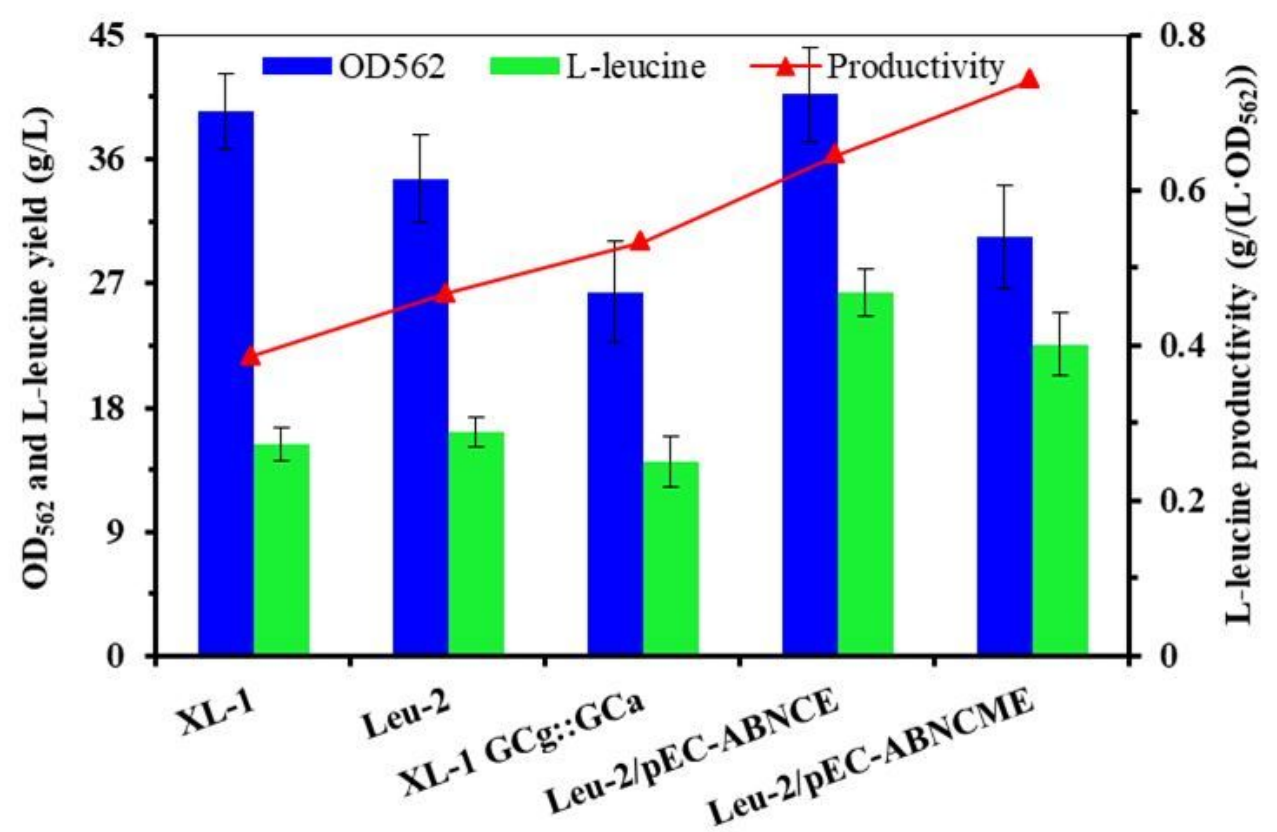

Strains

Figure 3

The synthesis capacity of L-leucine of original strain and recombinant strains in the fermentation medium. The data represent mean values and standard deviations obtained from three independent cultivations. 
a
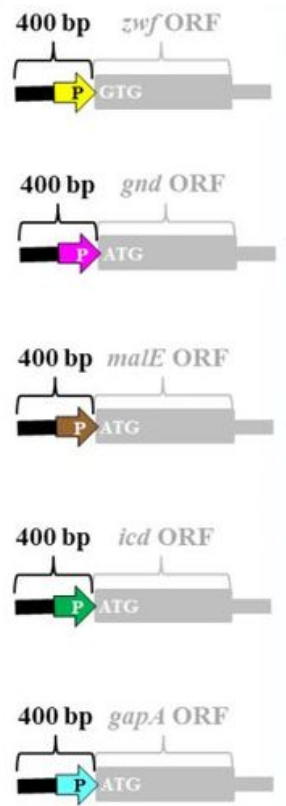

b

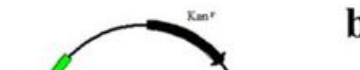

b

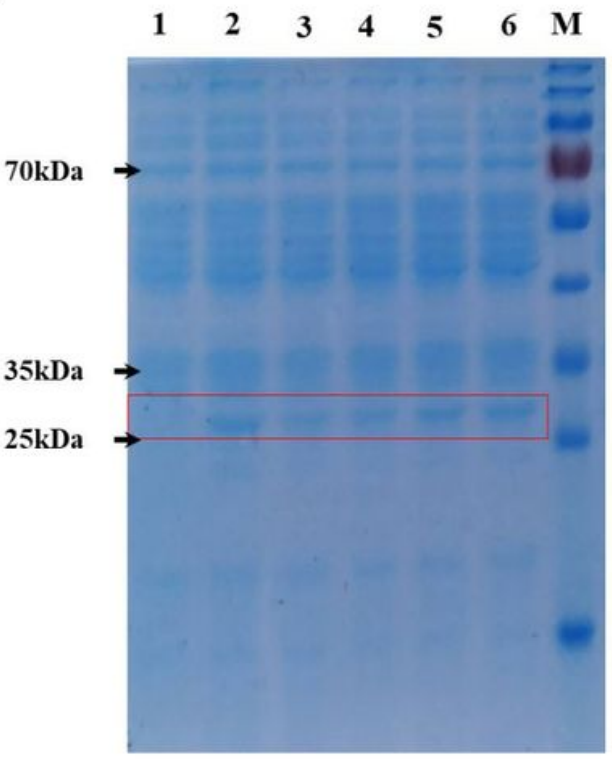

Figure 4

The promoter activity of key enzymes involved in NADPH regeneration. (a) The strategies for constructing the promoter-probe vectors. (b) Analyzing the CAT expression of strains under the different promoters by SDS-PAGE. Lane 1 E. coli pDXW-11; Lane 2 E. coli pDXW-11-P $P_{\text {gapA; }}$ Lane 3 E. coli pDXW-11-P malE; Lane 4 E. coli pDXW-11- $P_{\text {icd }}$; Lane 5 E. coli pDXW-11- $P_{\text {zwf }}$ Lane 6 E. coli pDXW-11- $P_{\text {gnd }}$; Lane M Protein marker. The blot in the red box is the CAT. 

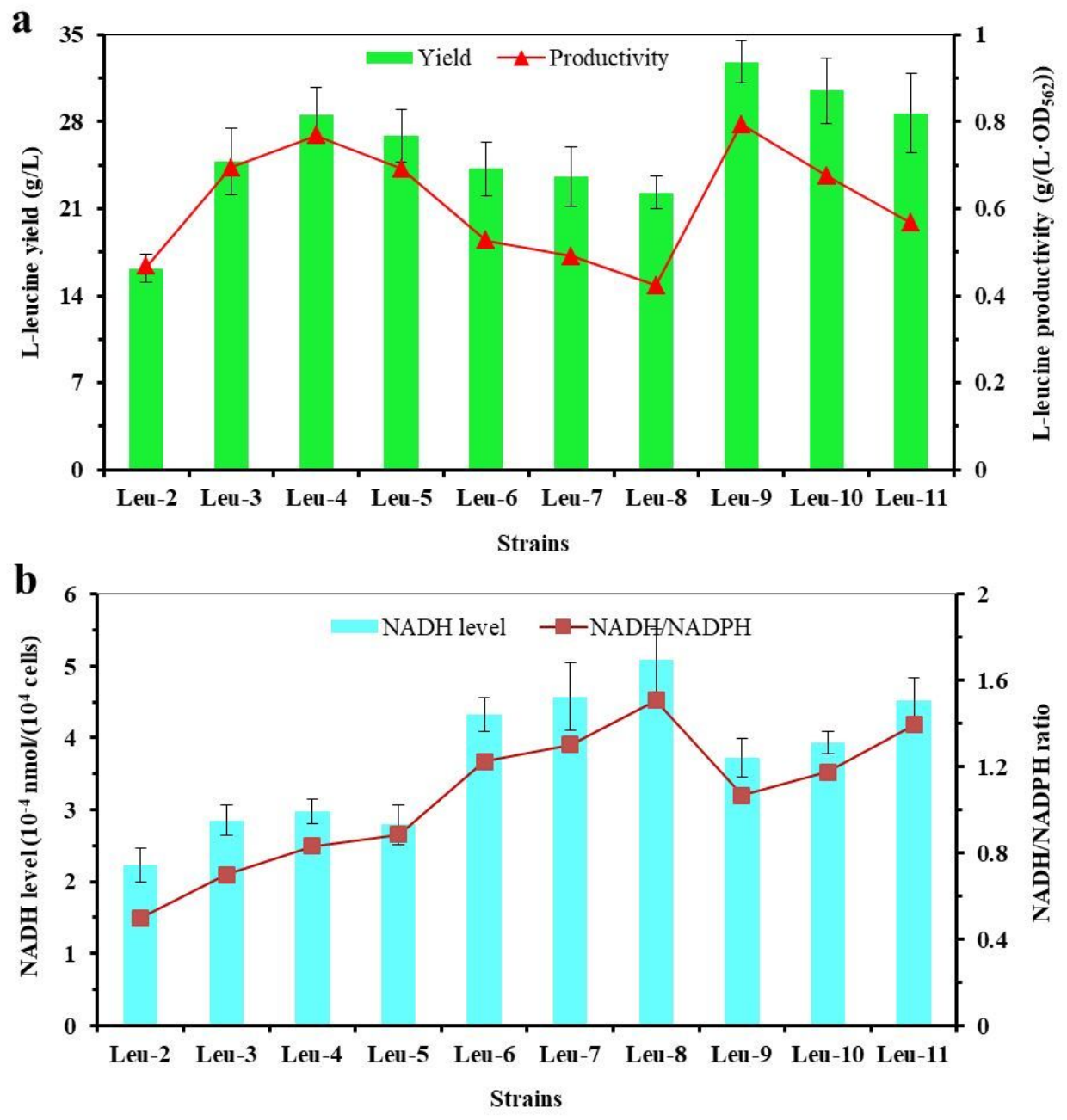

Figure 5

The positive effects of the mutate promoters of the $z w f$ and $i c d_{c g}$ on L-leucine production. (a) L-leucine yield and productivity of recombinant strains with different promoters of the $z w f$ and $i c d_{\mathrm{Cg}}$. (b) NADH level and NADH/NADPH ratio of recombinant strains with different promoters of the $z w f$ and $i c d_{\mathrm{Cg}}$. The data represent mean values and standard deviations obtained from three independent cultivations.

\section{Supplementary Files}

This is a list of supplementary files associated with this preprint. Click to download.

- Supplementarymaterial.docx 